Check for updates

Cite this: RSC Adv., 2021, 11, 1250

Received 3rd November 2020 Accepted 6th December 2020

DOI: $10.1039 / \mathrm{dOra09347e}$

rsc.li/rsc-advances

\section{A New ternary organometallic Pd(II)/Fe(III)/Ru(III) self-assembly monolayer: the essential ensemble synergistic for improving catalytic activity $\dagger$}

\author{
Ruirui Ren, ${ }^{a}$ Pingping Huang, ${ }^{a}$ Wuduo Zhao, (D) ${ }^{a}$ Tiesheng Li, (D) *a Minghua Liu (D) *bc \\ and Yangjie Wu iD *a
}

\begin{abstract}
The synergistic catalytic effect in a hetero-trimetallic catalytic monolayer is one of the intriguing topics because the additive effects of the second or third component play an important role in improving the activity. In this paper, a new Schiff-base organometallic nanosheet containing Pd/Fe/Ru immobilized on graphene oxide (GOQH-Pd/Fe/Ru) was prepared and characterized. The catalytic performance of $\mathrm{GO} \mathrm{aH}-\mathrm{Pd} / \mathrm{Fe} / \mathrm{Ru}$ and synergistic effect were systematically investigated. GO@H-Pd/Fe/Ru was found to be an efficient catalyst with higher turnover frequency (TOF) $\left(26892 \mathrm{~h}^{-1}\right)$ and stability with recyclability of at least 10 times in the Suzuki-Miyaura coupling reaction. The deactivation mechanism was caused by the aggregation of the active species, loss of the active species, the changes of the organometallic complex, and active sites covered by adsorbed elements during the catalytic process. GOQH-Pd/Fe/Ru was a heterogeneous catalyst, as confirmed by kinetic studies with in situ FT-IR, thermal filtration tests

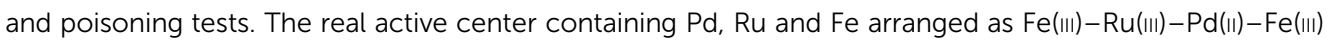
was proposed. Although Ru(III) and Fe(III) were shown to be less active or inactive, the addition of Fe and Ru could effectively improve the entire activity by their "indirect" function, in which Fe or Ru made Pd more negative and more stable. The ensemble synergistic effect between metals, the ligand and support was described as a process in which the electron was transferred from $\mathrm{GO}$ via ligand to $\mathrm{Ru}$, and then to $\mathrm{Pd}$ or from Fe to $\mathrm{Pd}$ to make $\mathrm{Pd}$ more negative, promoting the oxidation addition with aryl halide. Also, the vicinity of Ru around Pd as the promoter adsorbed aryl boronic acid, which facilitates its synergism to react with the oxidation intermediate to the trans-metallic intermediate.
\end{abstract}

\section{Introduction}

The design and synthesis of heterogeneous catalysts are very important research areas, expanding from a mono- to multimetallic catalyst, in which monometallic heterogeneous catalysts have been deeply studied. ${ }^{1}$ For hetero-bimetallic catalysts, an investigation on the relationship between their activity and structure is deeply studied for understanding the synergism between the different components. ${ }^{2-4}$ Recently, the synergistic catalysis with trimetallic catalysts have received considerable interest, ${ }^{5}$ and the real active centers remain unknown because each component is responsible for different steps in the overall transformation. ${ }^{6}$ Meanwhile, there has been rapidly growing

${ }^{a}$ College of Chemistry and Molecular Engineering, Zhengzhou University, Kexuedadao 100, Zhengzhou, 450001, P. R. China. E-mail: lts34@zzu.edu.cn; Fax: +86-37167766667

${ }^{b}$ Henan Institute of Advanced Technology, Zhengzhou University, Kexuedadao 100, Zhengzhou 450001, Henan Province, P. R. China

${ }^{'}$ Beijing National Laboratory for Molecular Science, Institute of Chemistry, Chinese Academy of Sciences, Zhongguancun North First Street 2, Beijing 100190, P. R. China $\dagger$ Electronic supplementary information (ESI) available. See DOI: 10.1039/d0ra09347e interest in multi-component catalysts, in which improving the activity and reducing expenses are considered to be key issues for heterogeneous catalyst, ${ }^{7,8}$ and are particularly important for noble metals. ${ }^{9-12}$

In catalytic systems, homogeneous catalysis has some drawbacks, such as the problem of the residue and recycling of the catalyst. ${ }^{13}$ A heterogeneous catalyst immobilized or fixed on a support can be easily recycled. ${ }^{\mathbf{1 4}}$ The heterogeneous Pdcatalyzed Suzuki cross-coupling reaction is a remarkably useful tool in organic synthesis. ${ }^{15}$ Therefore, substituting palladium with less expensive doped transition metals is expected for achieving higher activity and reducing the catalyst costs. For example, some economic transition metals include nickel with its charge-donating ability, ${ }^{4,9}$ and the charge transferring and stabilizing property of Fe. ${ }^{\mathbf{8} 16}$ Ruthenium is one of the cheapest precious metals having broad application prospects, ${ }^{17,18}$ and has long been considered as one of the effective components in a catalyst. ${ }^{19,20}$ Synergetic effects with dopants for an efficient Pd-based, Fe-based and Ru-based heterogeneous bimetallic catalyst are intensively being investigated. ${ }^{21-29}$ If the multimetallic catalyst contains $\mathrm{Pd}, \mathrm{Fe}$ and $\mathrm{Ru}$ or another 
component, they will show efficient synergism due to the consecutive effect of different active centers in reactions. ${ }^{30-33}$

The development of a multi-metallic catalyst is motivated by the idea to overcome the problems encountered in heterogeneous systems. The preparation of trimetallic catalysts, in which most of them are in the form of an alloy, involves the core-shell being synthesized by a complicated method and their reproducibility is difficult to control. ${ }^{34}$ Therefore, developing an efficient multi-metallic catalytic system must overcome more difficulties, including the preparation method, assembling each component to control the electronic effects between different metals, the distribution of active sites, and ensuring that they not only act as a promoter, but also provide stabilization for the active center. Meanwhile, the interaction between each metal and the overall performance impact are an urgent problem to be solved. $^{35}$

It is well known that the catalytic surfaces are correlated to the activity. The precise surface modification by introducing proper metals or constructing proper morphology can easily tune the catalytic properties. ${ }^{36,37}$ The self-assembly (SA) was an efficient way to get the desired structure with special properties, which can offer the desired controllability of the orientation and stable monolayer. ${ }^{38-45}$ Previous studies showed that the activity of the bimetallic catalysts, or their monolayer and their recyclability, could be enhanced by tuning their orientation of the organometallic molecular, component, morphology and distributions of the active species, relating to the electrical characteristics of the supports, ligands, and synergism of the mono- or hetero-bimetallic catalytic films. ${ }^{\mathbf{4 , 1 6 , 3 5 , 3 7 , 3 9 , 4 4 , 4 6 - 5 5}}$

By now, multicomponent catalysts have made great progress, such as multi-metallic NPs, who have more variables available for tuning their catalytic activity. ${ }^{56}$ Research on introducing a third or fourth metal to the ordered catalytic molecular monolayer is limited. It is urgently needed to focus on how to prepare ordered heterogeneous trimetallic catalytic films at the molecular level with the proper components, in addition to basic research on what factors affect the catalytic activity and rationality. Up to now, there have only been a few studies in the literature on the rational design in the directional order heterogeneous trimetallic catalytic monolayer.

Meanwhile, appropriate supports that improve the dispersion and the utilization of noble catalysts have attracted much attention. This is because the intrinsic activity and selectivity can vary strongly, depending on the physical properties of the supports. ${ }^{57-60}$ Graphene oxide as an efficient support was recognized as one of the ideal candidates because of its large surface area, high stability, unique two-dimensional structure. ${ }^{61,62}$ Thus, there are a variety of functional groups through which covalent self-assembly films can be anchored. ${ }^{63-65}$

Ligand design is also an integral part of the heterogeneous catalyst, and is promising for tuning the metal coordination sphere and stabilizing the active sites available for substrate binding during catalytic cycling. ${ }^{66}$ The Schiff-base ligand is a privileged ligand, which is capable of stabilizing many different metals and controlling the metal properties in many catalytic transformations. ${ }^{67}$

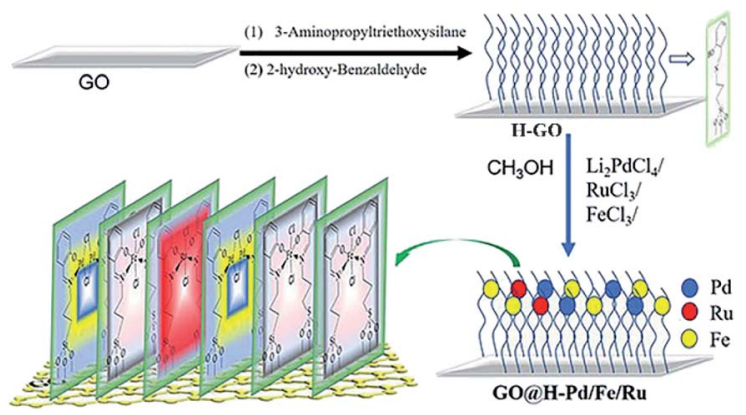

Scheme 1 Preparation process of the GOQH-Pd/Fe/Ru monolayer.

In this paper, an ordered hetero-trimetallic catalytic monolayer containing selected $\mathrm{Pd},{ }^{68} \mathrm{Fe}^{69}$ and $\mathrm{Ru}^{70}$ metals coordinated with the Schiff-base ligand supported on GO by self-assembly was presented. It is expected to provide efficiency, recycling ability and a reduction in the overall economic cost. With the self-assembly method and the permutation of selecting the ligand, supports, and combination of different metals, the origin of the high activity and the relationship between the activity and the structure, and the synergism between the doped metals will be deeply explored and elucidated at molecular level using the Suzuki-Sonogashira coupling reaction as a template.

\section{Experimental}

2.1. Reagents and instruments, and the general procedure

Chemical reagents and instruments used for the characterization, general synthesis and general procedure for the coupling reaction and RactIR recording are presented in ESI. $\dagger$

\subsection{Preparation and characterization of the GO@H-Pd/Fe/ Ru monolayer}

The main target here was that the three different metals, having such a relation to each other, were arranged in a self-assembly monolayer that was fabricated as depicted in Scheme 1. The preparation processes of the GO@H-Pd/Fe/Ru monolayer were characterized by XRD, FT-IR, RS, SEM, TEM, XPS, ESI, and BEI (see $\left.\mathrm{ESI}_{\dagger}\right)^{\mathbf{1 6}}$

\section{Results and discussion}

\subsection{Characterization of GO@H-Fe ${ }_{95.73} \mathrm{Pd}_{4.26} \mathrm{Ru}_{0.01}$}

The XRD patterns of GO, H-GO and GO@H-Fe $\mathbf{~}_{\mathbf{9 5 . 7 3}} \mathbf{P d}_{4.26} \mathbf{R u}_{\mathbf{0 . 0 1}}$ were measured (Fig. S1 $\dagger$ ). Two diffraction peaks were observed at $2 \theta$ values of $42.5^{\circ}$ and $10.9^{\circ}$, corresponding to the (100) and (002) crystal planes of GO, respectively. In the case of $\mathbf{H}-\mathbf{G O}$ and GO@H-Fe $\mathbf{9 5 . 7 3}_{\mathbf{9}} \mathbf{P d}_{\mathbf{4 . 2 6}} \mathbf{R u}_{\mathbf{0 . 0 1}}$, they shifted to a small angular direction compared to GO. According to the Bragg equation,

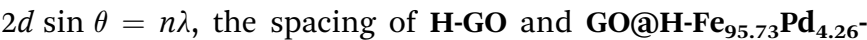
$\mathbf{R u}_{\mathbf{0 . 0 1}}$ increased due to the inserted ligand and organometallic compound.

From FT-IR (Fig. S2 $\dagger$ ), a peak could be observed due to the $\mathrm{O}-\mathrm{H}$ group at $3430 \mathrm{~cm}^{-1}$. A peak at $1729 \mathrm{~cm}^{-1}$ corresponding to the stretching vibration of the carboxyl group, and three peaks 
at $1622 \mathrm{~cm}^{-1}, 1221 \mathrm{~cm}^{-1}$, and $1053 \mathrm{~cm}^{-1}$ were the bending vibrations of $\mathrm{C}-\mathrm{OH}$ and $\mathrm{C}-\mathrm{O}$ on GO. After modification with the Schiff base, distinct peaks at 1105 and $1042 \mathrm{~cm}^{-1}$ corresponding to Si-O were observed. The stretching vibrational peak of $\mathrm{C}=\mathrm{N}$ in the ligand at approximately $1636 \mathrm{~cm}^{-1}$ shifted to a lower frequency. This was due to the coordination of $\mathrm{C}=\mathrm{N}$ with the Pd, Ru and Fe ions to form GO@H-Fe ${ }_{95.73} \mathbf{P a}_{4.26} \mathbf{R u}_{\mathbf{0 . 0 1}}$.

The Raman spectra in the preparation process of GO@H$\mathbf{F e}_{\mathbf{9 5 . 7 3}} \mathbf{P d}_{\mathbf{4 . 2 6}} \mathbf{R u}_{\mathbf{0 . 0 1}}$ are shown in Fig. S3, $\dagger$ which had two characteristic peaks at 1347 and $1596 \mathrm{~cm}^{-1}$ attributed to the D (C $\left.\mathrm{sp}^{2}\right)$ and $\mathrm{G}\left(\mathrm{C} \mathrm{sp}^{3}\right)$ bands, respectively. ${ }^{71}$ The intensity ratio of $I_{\mathrm{D}} /$ $I_{\mathrm{G}}$ increased from 0.95 to 0.97 and 0.99 , which could be caused by two possible reasons. One reason was that some of the functional groups were reduced. The other was that the GO surface gradually became disordered during the functionalization process.

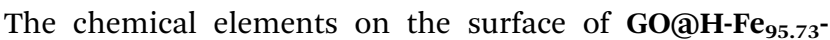
$\mathbf{P d}_{\text {4.26 }} \mathbf{R u}_{\mathbf{0 . 0 1}}$ obtained were measured by XPS (Fig. S4 $\dagger$ ). The energy level peaks of Pd 3d, C 1s, Si 2s, N 1s, O 1s, Fe 2p, Cl 2p, and $\mathrm{Ru} 3 \mathrm{~d}$ were present in Fig. $\mathrm{S} 4 \mathrm{a} . \dagger$ The $\mathrm{N} 1 \mathrm{~s}$ showed the characteristic peak at $400.0 \mathrm{eV}$ in Fig. S4b. $\dagger$ The Ru 3d XPS

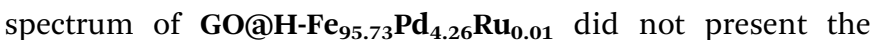
binding energies of Ru due to there being only a small amount of $\mathrm{Ru}$, and quite close binding energies of $\mathrm{C} 1 \mathrm{~s}$ (Fig. S4c $\dagger$ ). ${ }^{72}$ There were two peaks with corresponding binding energies, $725.9 \mathrm{eV}$ and $711.9 \mathrm{eV}$, of Fe $2 \mathrm{p}$ that were observed, as shown in Fig. S4d. $\dagger$ The binding energies, $343.6 \mathrm{eV}$ and $338.6 \mathrm{eV}$, were denoted as the binding energy of $\mathrm{Pd} 3 \mathrm{~d}$, and showed that $\mathrm{Pd}(\mathrm{II})$ existed in GO@H-Fe $\mathbf{9 5 . 7 3}_{\mathbf{9}} \mathbf{P d}_{\mathbf{4 . 2 6}} \mathbf{R u}_{\mathbf{0 . 0 1}}$ (Fig. S4e $\dagger$ ).

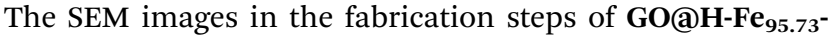
$\mathbf{P d}_{4.26} \mathbf{R u}_{\mathbf{0 . 0 1}}$ were measured (Fig. S5 $\dagger$ ). Morphologies of GO exhibited the two-dimensional layered fold structures. After modification by the Schiff base ligand (H-GO), the layered structure showed more fold characteristics. The SEM image of GO@H-Fe 95.73 $\mathbf{P d}_{4.26} \mathbf{R u}_{\mathbf{0 . 0 1}}$ showed a neat sheet structure, indicating the ordered modification of the Schiff-based complexes

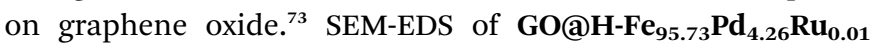
showed the presence of palladium, iron and ruthenium on the surface of the catalyst in Fig. S6. $\uparrow$ This also indicated that the relative contents of different $\mathrm{Pd}, \mathrm{Fe}$ and $\mathrm{Ru}$ metals were distributed on GO.

The TEM images in the preparation process of GO@H$\mathbf{F e}_{\text {95.73 }} \mathbf{P d}_{\text {4.26 }} \mathbf{R u}_{\mathbf{0 . 0 1}}$ were obtained and are shown in Fig. S7. $\dagger$ A sheet-like structure of GO was observed (Fig. S7a $\dagger$ ). Similar lamellar structures can be observed when the surface of GO was modified with a Schiff base, as shown in Fig. S7b. $\dagger$ From the TEM images of GO@H-Fe $\mathbf{9 5 . 7 3}_{\mathbf{9}} \mathbf{P d}_{\mathbf{4 . 2 6}} \mathbf{R u}_{\mathbf{0 . 0 1}}$, an obvious lamellar was observed (Fig. S7c $\dagger$ ).

To further characterize the corresponding $\mathbf{G O @ H - F _ { \mathbf { 9 5 . 7 3 } ^ { - } }}$ $\mathbf{P d}_{\text {4.26 }} \mathbf{R u}_{\text {0.01 }}$ pore diameter distribution, BET was measured (Fig. S8 $\dagger$ ). GO, H-GO and GO@H-Fe ${ }_{95.73} \mathbf{P d}_{4.26} \mathbf{R u}_{\mathbf{0 . 0 1}}$ isotherms were denoted to type IV, and GO@H-Fe $\mathbf{9}_{\mathbf{9 5 . 7 3}} \mathbf{P d}_{\mathbf{4 . 2 6}} \mathbf{R} \mathbf{u}_{\mathbf{0 . 0 1}}$ was a H4 hysteresis loop $\left(11.2948 \mathrm{~m}^{2} \mathrm{~g}^{-1}\right)$. GO and H-GO were a H3 hysteresis loop $\left(2.0953 \mathrm{~m}^{2} \mathrm{~g}^{-1}, 4.8058 \mathrm{~m} 2 \mathrm{~g}^{-1}\right)$. GO@H-Fe $\mathbf{9 5 . 7 3}^{-}$ $\mathbf{P d}_{\text {4.26 }} \mathbf{R u}_{\mathbf{0 . 0 1}}$ was a mesoporous catalyst with pore sizes from 2 to $50 \mathrm{~nm}^{.74}$
EIS spectroscopy was widely utilized to investigate the electron transmission efficiency. The EIS diagrams for GO, H-GO and GO@H-Fe ${ }_{95.73} \mathbf{P d}_{\mathbf{4 . 2 6}} \mathbf{R u}_{\mathbf{0 . 0 1}}$ were measured (Fig. S9†). Theoretically, the arc in the EIS spectrum represents the impedance of the catalyst supported on the electrochemical nickel foam electrode. Smaller arcs represented faster electron transfer efficiency, and the diameter of the catalyst $\mathbf{G O @ H - \mathbf { F e } _ { \mathbf { 9 5 . 7 3 } }} \mathbf{-}^{-}$ $\mathbf{P d}_{\text {4.26 }} \mathbf{R u}_{\mathbf{0 . 0 1}}$ was smaller than that of GO and H-GO, indicating that GO@H-Fe ${ }_{\mathbf{9 5 . 7 3}} \mathbf{P d}_{\mathbf{4 . 2 6}} \mathbf{R u}_{\mathbf{0 . 0 1}}$ showed a higher charge transfer capacity due to the proper arrangement of these three metallic complexes. $^{75}$

For circumstantial evidence, the preparation process of the ligand monolayer and its complex monolayer on hydrophilic silicon by SAMs was characterized by AFM. AFM images of the prepared Si@OH, Si@H, and Si@H-Fe/Pd/Ru are presented in Fig. S10a-c. $\dagger$ The images showed the regular structures associated with different roughnesses in different steps, and the roughness was $0.45 \mathrm{~nm}, 1.13 \mathrm{~nm}$, and $0.80 \mathrm{~nm}$, respectively. It was evidence of the ordered arrangement of the molecules in the monolayer during SAMs, indicating that uniform monolayers were formed.

All characterizations obtained above provided evidence that the GO@H-Fe $\mathbf{~}_{\mathbf{9 5 . 7 3}} \mathbf{P d}_{4.26} \mathbf{R u}_{\mathbf{0 . 0 1}}$ monolayer on the surface of GO was fabricated.

\subsection{Evolution of the catalytic properties of GO@H- $\mathrm{Fe}_{95.73} \mathrm{Pd}_{4.26} \mathrm{Ru}_{0.01}$}

3.2.1 Optimization for the Suzuki coupling reaction. The

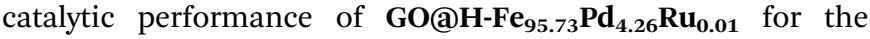
Suzuki coupling reaction was investigated (Table S1, $\uparrow$ entries 115). Decreasing the reaction time, reducing the reaction temperature, and increasing the substrate amount resulted in a decrease in the reaction yield (entries 16-19). Under the reaction conditions $\left(80{ }^{\circ} \mathrm{C}, 1 \mathrm{~h}\right.$, water-ethanol ratio of $3: 1$, $\mathrm{Na}_{2} \mathrm{CO}_{3}$ ), 99\% yield of 4-phenyltoluene was obtained. The optimized reaction conditions were selected, as indicated in the following experimental section (entry 7 ).

3.2.2 Effect of the metal ratio $(\mathrm{Fe} / \mathrm{Pd} / \mathrm{Ru})$ on the catalytic activity. Different ratios of $\mathrm{Fe} / \mathrm{Pd} / \mathrm{Ru}$ in the catalyst were used to investigate the catalytic activity under the optimized reaction conditions shown in Table S2. $\dagger$ A yield of 99\% was obtained for GO@H-Fe 95.73 $_{\text {Gd }} \mathbf{P d}_{\mathbf{4 . 2 6}} \mathbf{R u}_{\mathbf{0 . 0 1}}$, and the TOF was 17247 (entry 9). Although the TOF of GO@H-Fe ${ }_{\mathbf{9 5 . 7 3}} \mathbf{P d}_{\mathbf{4 . 2 6}} \mathbf{R u}_{\mathbf{0 . 0 1}}$ was 21 714, the yield was only $76 \%$ (entry 10 ). In the case of other bimetallic catalysts (entries 1-8), lower TOF values were obtained

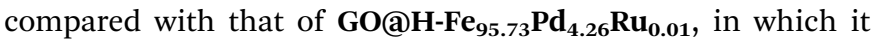
showed that the doped $\mathrm{Fe}$ and $\mathrm{Ru}$ could further enhance the catalytic activity.

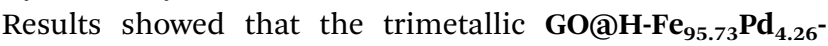
$\mathbf{R u}_{\mathbf{0 . 0 1}}$ monolayer with proper ratio exhibited better catalytic activity than others, indicating that the concerted electronic effects between these three metals exhibited a positive synergism. ${ }^{30}$ Compared to GO@H-Pd, GO@H-Fe, GO@H-Ru, GO@H-

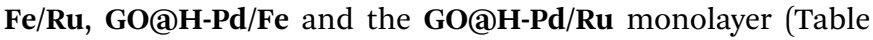
$\mathrm{S} 2, \dagger$ entries 1-6), the GO@H-Pd/Fe/Ru monolayer showed higher activity and stability, while preserving the beneficial 


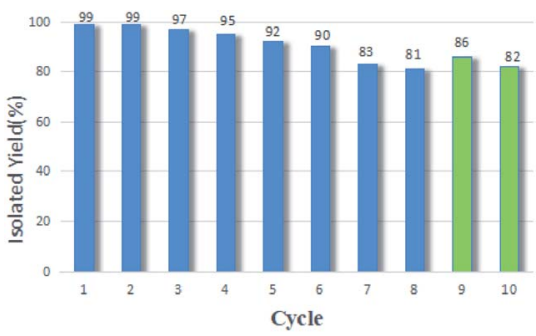

Fig. 1 The recycle experiments of $\mathrm{GO} @ \mathrm{H}-\mathrm{Fe}_{95.73} \mathrm{Pd}_{4.26} \mathrm{Ru}_{0.01}$.

catalytic activity of the Pd metallic monolayer (entries 7-10). The strategy revealed the great potential in the fundamental studies and preparation of the novel catalyst by utilizing the multimetallic monolayer. Considering the cost and environmental requirements, GO@H-Fe ${ }_{\mathbf{9 5 . 7 3}} \mathbf{P d}_{\mathbf{4 . 2 6}} \mathbf{R u}_{\mathbf{0 . 0 1}}$ was selected for the following investigation on the catalytic properties.

3.2.3 Catalytic properties of GO@H-Fe ${ }_{95.73} \mathbf{P d}_{4.26} \mathbf{R u}_{0.01}$. The control experiments were designed to explore the influence of the carrier, ligand, and preparation methods on the catalytic performance. There were no products with GO or H-GO (Table $\mathrm{S} 3, \uparrow$ entries 1 and 2). The effect of the added GO was studied (entries 3-6). $\mathrm{Li}_{2} \mathrm{PdCl}_{4}(0.00287 \% \mathrm{mmol}) / \mathrm{FeCl}_{3} \cdot 6 \mathrm{H}_{2} \mathrm{O} / \mathrm{RuCl}_{3}$ $\cdot x \mathrm{H}_{2} \mathrm{O}$ added to the reaction mixture gave $84 \%$ yield (entry 3 ). When a mixture of Schiff base ligands and $\mathrm{Li}_{2} \mathrm{PdCl}_{4}(0.00287 \%$ $\mathrm{mmol}) / \mathrm{FeCl}_{3} \cdot 6 \mathrm{H}_{2} \mathrm{O} / \mathrm{RuCl}_{3} \cdot x \mathrm{H}_{2} \mathrm{O}$ were used as catalyst, only $42 \%$ yield was obtained (entry 4 ). The yield of $\mathrm{GO} / \mathrm{Li}_{2} \mathrm{PdCl}_{4} / \mathrm{FeCl}_{3}$ $\cdot 6 \mathrm{H}_{2} \mathrm{O} / \mathrm{RuCl}_{3} \cdot x \mathrm{H}_{2} \mathrm{O}$ was $64 \%$ (entry 5 ). However, the yield of $\mathrm{GO} /$ Ligand $/ \mathrm{Li}_{2} \mathrm{PdCl}_{4} / \mathrm{FeCl}_{3} \cdot 6 \mathrm{H}_{2} \mathrm{O} / \mathrm{RuCl}_{3} \cdot x \mathrm{H}_{2} \mathrm{O}$ was only $49 \%$ (entry $6)$. In the case of (entry 7 ), higher yield and TOF values were obtained, showing that the ordered self-assembly metallic monolayer was an efficient catalyst (entry 7). Using silica as a support gave a better yield (entry 8), but it was lower than that of $\mathbf{G O @ H - F e} \mathbf{9 5 . 7 3}_{\mathbf{9}} \mathbf{P d} \mathbf{d}_{\mathbf{4 . 2}} \mathbf{R u}_{\mathbf{0 . 0 1}}$, indicating that $\mathbf{G O}$ played a great role for enhancing the activity.

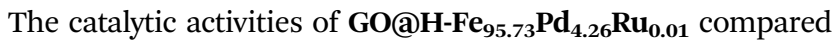
with other reported nanoporous catalysts are summarized in
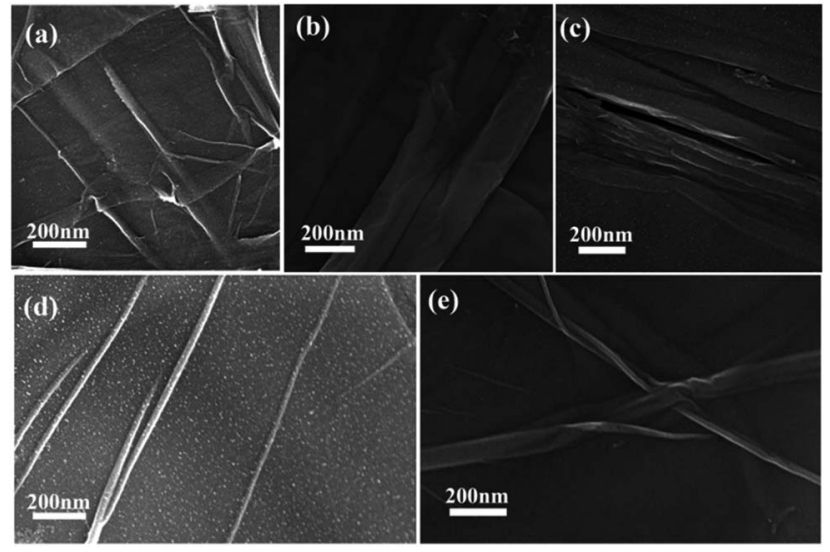

Fig. 2 SEM images of the process of the catalyst and reused catalyst: (a) 0 min, (b) after the 1st run, (c) after the 4th run, (d) after the 8th run, and (e) after the 10th run.
Table S4. $\dagger$ GO@H-Fe ${ }_{95.73} \mathbf{P d}_{\mathbf{4 . 2 6}} \mathbf{R u}_{\mathbf{0 . 0 1}}$ had a lower loading and a higher TOF value.

To investigate the scope of the substrates, the SuzukiSonogashira coupling reactions catalyzed by $\mathbf{G O @ H - F \mathbf { F 5 . 7 3 } ^ { - }}$ $\mathbf{P d}_{\text {4.26 }} \mathbf{R u}_{\mathbf{0 . 0 1}}$ were conducted by reacting aryl halides with aryl boric acid derivatives (Table $\mathrm{S} 5 \dagger$ ). When aryl iodine and benzene boric acids were used, 99\% yield was obtained (Table $\mathrm{S} 5, \dagger$ entries 1 and 2). When aryl bromides having electrondonor or electron-receptor functional groups and benzene boric acids were used, higher yields were obtained (Table S5, $\dagger$ entries 3-13). The different substitution groups of aryl bromides were compared, and the yield of para-substituted or metasubstituted were higher than that of ortho-substituted aryl bromides due to the steric hindrance (Table S5, $\dagger$ entries 8-13). However, in the case of the chlorobenzene used, the results were unsatisfactory. In addition, the phenylboronic derivatives showed higher reactivity than heterocyclic borate. It was the fact that the heteroatoms may coordinate with the active metal centers, resulting in the deactivation of the active metal.

3.2.4 Recycling and stability of GO@H-Fe ${ }_{95.73} \mathrm{Pd}_{4.26} \mathrm{Ru}_{0.01}$.

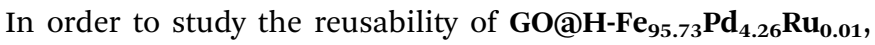
the recycling experiments were carried out in the optimized condition. As shown in Fig. 1, GO@H-Fe $\mathbf{9 5 . 7 3}_{\mathbf{9}} \mathbf{P d}_{\mathbf{4 . 2 6}} \mathbf{R u}_{\mathbf{0 . 0 1}}$ showed excellent stability upon reuse, which was better than that of the GO@H-Pd/Fe monolayer. ${ }^{\mathbf{1 6}}$ After eight cycles, the catalyst maintained its high efficiency without causing significant loss. By extending the catalytic time to two hours, the yield was $82 \%$ at the 10 th recycle. It was attributed to the loss of the active centers, according to the results of the amount of metals measured by ICP-AES before and after being recycled. The amount of metals was Pd: $3.31 \times 10^{-6} \mathrm{mmol} \mathrm{mg}^{-1}$ (fresh sample: $2.87 \times 10^{-5}$ ), Fe: $1.48 \times 10^{-6} \mathrm{mmol} \mathrm{mg}^{-1}$ (fresh sample: $7.98 \times 10^{-5}$ ), Ru: $4.79 \times 10^{-7} \mathrm{mmol} \mathrm{mg}^{-1}$ (fresh sample: $8.70 \times 10^{-7}$ ) at the 10 th recycle.

3.2.5 Investigation of the deactivation mechanism of GO@H-Fe $\mathbf{9 5 . 7 3}_{\mathbf{9}} \mathbf{P d}_{\mathbf{4 . 2 6}} \mathbf{R u _ { 0 . 0 1 }}$. It was important to understand the deactivation mechanism for the heterogeneous catalysts. To clarify

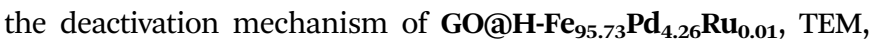

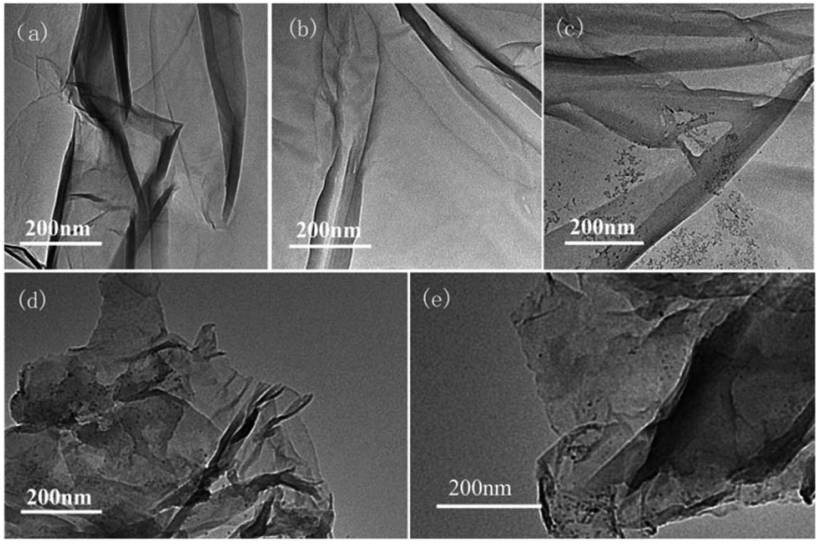

Fig. 3 TEM images of the process of the catalyst and reused catalyst: (a) 0 min, (b) after the 1st run, (c) after the 4th run, (d) after the 8th run, and (e) after the 10th run. 

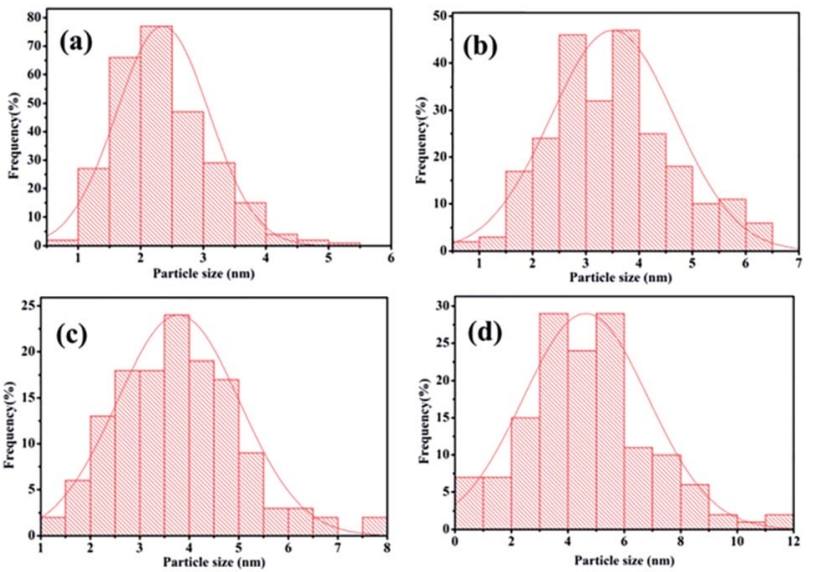

Fig. 4 Histogram of the $\mathrm{Pd}(0)$ nano-cluster diameters during the catalytic process from Fig. 3: (a) $2.35 \mathrm{~nm}$ after the 1st run, (b) $3.50 \mathrm{~nm}$ after the 4 th run, (c) $3.78 \mathrm{~nm}$ after the 8 th run, (d) $4.32 \mathrm{~nm}$ after the 10 th run

SEM, XPS, and the content of metals in the catalyst before and after it was recycled were used to closely investigate the catalyst. ${ }^{76}$

First, the amount of metals was Pd: $3.31 \times 10^{-6} \mathrm{mmol} \mathrm{mg}^{-1}$ (fresh sample: $2.87 \times 10^{-5}$ ), Fe: $1.48 \times 10^{-6} \mathrm{mmol} \mathrm{mg}^{-1}$ (fresh sample: $7.98 \times 10^{-5}$ ), Ru: $4.79 \times 10^{-7} \mathrm{mmol} \mathrm{mg}^{-1}$ (fresh sample: $8.70 \times 10^{-7}$ ) at the 10 th recycle measured by ICP-AES. The loss of the active centers was one reason for the deactivation of the catalyst, according to the results of the amount of metals in the catalyst before and after being recycled.

Second, the catalyst morphology before and after being used was measured with SEM, as shown in Fig. 2, in which the morphology and structure remained the original twodimensional layered structure during the reaction and after the 10th recycle. The TEM images of $\mathbf{G O @ H - F e} \mathbf{9 5}_{\mathbf{9} .73} \mathbf{P d}_{\mathbf{4 . 2 6}} \mathbf{R u}_{\mathbf{0 . 0 1}}$ are shown in Fig. 3, from which a histogram of the $\operatorname{Pd}(0)$ diameters during the catalytic process was plotted (Fig. 4). Obviously, a slight agglomeration with the increased size of the catalyst could be observed after the fourth, eighth, and tenth cycles, meaning that deactivation of the activity was clearly induced by a slight agglomeration of the active species. ${ }^{77}$

The analysis by TEM and SEM showed that GO@H-Fe $\mathbf{9 5 . 7 3}^{-}$ $\mathbf{P d}_{\text {4.26 }} \mathbf{R u}_{\mathbf{0 . 0 1}}$ maintained better stability during recycling. In fact, the heterogeneous surface contained a few active sites, and the changes of the surface environment could affect the catalyst
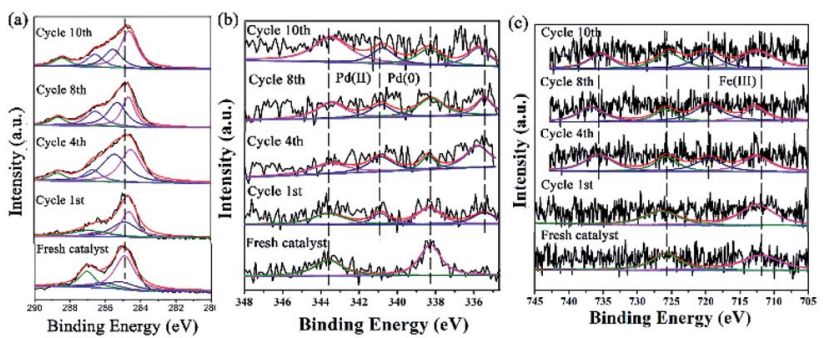

Fig. 5 The changes of the HR-XPS spectra of GO@H-Pd/Fe/Ru before and after being recycled. (a) $C 1 s+R u$ 3d; (b) Pd 3d; (c) Fe 2p. activity. ${ }^{78}$ It also indicated that the trimetallic complex monolayer acting as a pre-catalyst was likely a "reservoir" of the highly reactive species during the catalytic recycling. ${ }^{6}$

XPS is a versatile surface analysis technique that can be used for examining the compositional and chemical states in the catalyst. The XPS spectra of the catalyst monolayers were measured in order to understand what happened for the structure and composition on the catalytic surface before and after being recycled (Fig. 5).

Fig. 5a showed two peaks centered at 284.95 and $287.05 \mathrm{eV}$, respectively. It has been demonstrated that the $\mathrm{Ru}(0)$ and $\mathrm{Ru}(\mathrm{II})$ $3 \mathrm{~d}_{5 / 2}$ binding energies were not detected because of the low amount of $\mathrm{Ru} .^{72}$ The HR spectrum of $\mathrm{C} 1$ s was deconvoluted into four components, with the component at $284.78 \mathrm{eV}$ (C-C from GO) shifting to lower $\mathrm{BE}$, and $285.12 \mathrm{eV}(\mathrm{C}=\mathrm{C}$, derived from $\mathbf{G O}$ and ligand) shifting to higher BE, showing that the GO acted as an electron donor. The BE peak at $285.95 \mathrm{eV}$ corresponded to the $\mathrm{C}-\mathrm{O}$ group, and the $287.05 \mathrm{eV}$ peak attributed to the $-\mathrm{C}=\mathrm{O}$ group shifted to higher $\mathrm{BE}$, meaning that the structure changed during the catalytic process (Table $\mathrm{S} 6 \dagger$ ). The BE peaks of Pd $3 \mathrm{~d}$ centered at 343.60 and $338.60 \mathrm{eV}$ designated to $\operatorname{Pd}(\mathrm{II})$ were present before cycling (Fig. 5b). Two new peaks appeared at 340.88 and $335.49 \mathrm{eV}$ (denoted as $\mathrm{Pd}^{0}$ ) after the 1st recycle, indicating that $\mathrm{Pd}^{0}$ was formed during catalysis (Table S7 $\dagger$ ). The ratio of $\mathrm{Pd}^{0} / \mathrm{Pd}^{2+}$ increased with increasing recycling times (Table S8 $\dagger$ ), implying that more $\mathrm{Pd}^{0}$ appeared and resulted in an increased aggregation, which resulted in the deactivation of the catalyst. It was consistent with the results obtained from TEM (Fig. 3 and 4).

In the case of $\mathrm{Fe}(\mathrm{III})$, the $\mathrm{Fe} 2 \mathrm{p} \mathrm{BE}$ exhibited stability after the first run and a satellite peak appeared after the 2nd run, showing that the valence of $\mathrm{Fe}^{3+}$ increased (Table S7†). This enables the formation of $\mathrm{Fe}^{\delta+}$, from which the electrons were transferred from $\mathrm{Fe}$ to $\mathrm{Pd}$, resulting in the synergism between the metals to improve the activity (Fig. 5c).

The changes of the base elements on the surface of the catalyst were also investigated before and after being recycled (Fig. 6). There was a little residue of $\mathrm{Br} 3 \mathrm{~d}$ and $\mathrm{B} 1 \mathrm{~s}$ after being recycled, compared with that before recycle (Fig. 6a and b), indicating that these two elements might cover some active site after several reuse cycles, resulting in the deactivation of the catalyst. The $\mathrm{Cl} 2 \mathrm{p}$ peaks at $198.08 \mathrm{eV}$ and $199.82 \mathrm{eV}$ shifted to higher BE after catalysis (Fig. $6 \mathrm{c}$ and Table S9†), meaning that $\mathrm{Cl}$ coordinated with $\mathrm{Pd}$ and $\mathrm{Pd}^{2+}$. However, the peak of $\mathrm{N} 1 \mathrm{~s}$ (the $\mathrm{C}=\mathrm{N}$ double bond) at $401.51 \mathrm{eV}$ shifted to lower $\mathrm{BE}$ after being

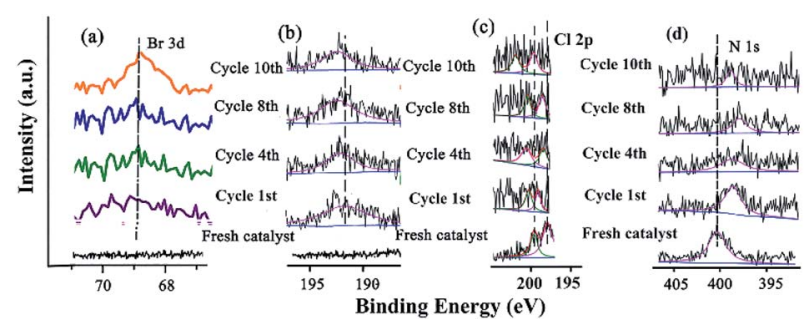

Fig. 6 XPS spectra of (a) Br 3d, (b) B 1s, (c) Cl 2p, and (d) N 1s before and after being recycled. 


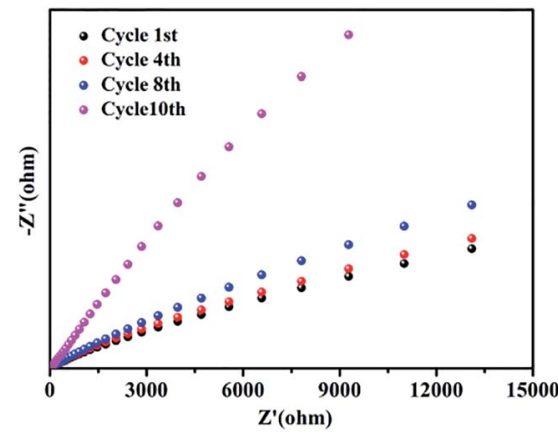

Fig. 7 The changes of the EIS of GOQH-Fe ${ }_{95.73} \mathrm{Pd}_{4.26} \mathrm{Ru}_{0.01}$ in the recycling experiments.

recycled several times (Fig. 6d and Table S9†), indicating that the precursor of the Schiff-based Pd(II) produced more active $\operatorname{Pd}(0)$ and a more available Schiff-base group appeared after more recycling. This free Schiff-base group could also stabilize and prevent $\operatorname{Pd}(0)$ from aggregating and leaching during the reaction. ${ }^{79}$ Meanwhile, the coordination of the $\mathrm{C}=\mathrm{N}$ double bond of the ligand to the $\mathrm{Pd}(0)$ site brings the $\mathrm{C}-\mathrm{Br}$ bond close to the Pd active site, which makes the oxidation easy due to the nature of the ligands around a redox-active metal center.

The stability of GO@H-Pd/Fe/Ru after being recycled was further investigated by electrochemical impedance spectroscopy (EIS). ${ }^{72}$ No obvious changes of the resistance were observed before the 8th recycling (Fig. 7), indicating the better stability of the catalyst. However, the charge transfer resistance was significantly increased in the 10th cycling due to the change of the structure of the metallic complexes in the monolayer, residue of substrates adsorbed, and increased formation of zero-palladium on the surface of the monolayer, resulting in the deactivation of the catalyst.

According to the results obtained above for the recycled catalyst characterized by the amount of metals in the catalyst,
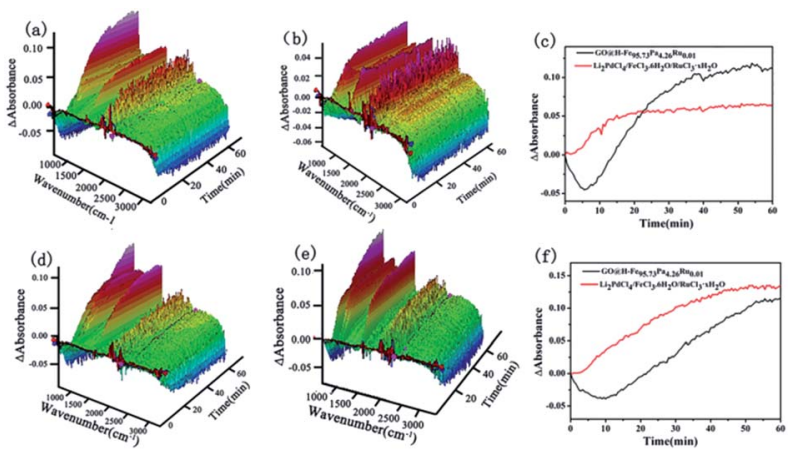

Fig. 8 ReactIR plots over time. (a) 3D map, GO@H-Fe ${ }_{95.73} \mathrm{Pd}_{4.26} \mathrm{Ru}_{0.01}$ at $80{ }^{\circ} \mathrm{C}$, (b) $3 \mathrm{D}$ map, $\mathrm{Li}_{2} \mathrm{PdCl}_{4} / \mathrm{FeCl}_{3} \cdot 6 \mathrm{H}_{2} \mathrm{O} / \mathrm{RuCl}_{3} \cdot x \mathrm{H}_{2} \mathrm{O}$ at $80{ }^{\circ} \mathrm{C}$, (c) kinetic curves of the catalytic reactions of $\mathrm{GO} a \mathrm{H}-\mathrm{Fe}_{95.73} \mathrm{Pd}_{4.26} \mathrm{Ru}_{0.01}$ and $\mathrm{Li}_{2} \mathrm{PdCl}_{4} / \mathrm{FeCl}_{3} \cdot 6 \mathrm{H}_{2} \mathrm{O} / \mathrm{RuCl}_{3} \cdot x \mathrm{H}_{2} \mathrm{O}$ using the bands at $754 \mathrm{~cm}^{-1}$ from (a) and (b) at $80{ }^{\circ} \mathrm{C}$. (d) $3 \mathrm{D}$ map, $\mathrm{GOaH}-\mathrm{Fe}_{95.73} \mathrm{Pd}_{4.26} \mathrm{Ru}_{0.01}$ at $65{ }^{\circ} \mathrm{C}$, (e) 3D map, $\mathrm{Li}_{2} \mathrm{PdCl}_{4} / \mathrm{FeCl}_{3} \cdot 6 \mathrm{H}_{2} \mathrm{O} / \mathrm{RuCl}_{3} \cdot x \mathrm{H}_{2} \mathrm{O}$ at $65{ }^{\circ} \mathrm{C}$, (f) kinetic curves of catalytic reactions of $\mathrm{GO} a \mathrm{H}-\mathrm{Fe}_{95.73} \mathrm{Pd}_{4.26} \mathrm{Ru}_{0.01}$ and $\mathrm{Li}_{2} \mathrm{PdCl}_{4} / \mathrm{FeCl}_{3} \cdot 6 \mathrm{H}_{2} \mathrm{O} / \mathrm{RuCl}_{3} \cdot x \mathrm{H}_{2} \mathrm{O}$ using the bands at $754 \mathrm{~cm}^{-1}$ from (d) and (e) at $65^{\circ} \mathrm{C}$.
SEM, TEM, XPS, and EIS, the inactivation mechanism of the catalyst mainly was the aggregation of the active species, leaching of the active species, the changes of the organometallic ligand, and the covered active sites by the adsorbed elements during the recycling process.

\subsection{Investigation of the catalytic mechanism}

3.3.1 Kinetic, hot filtration and poisoning experiments. It was a significant problem of how to identify the heterogeneous catalysis, by which elucidating the catalytic mechanism can be achieved. It was very helpful to solve this problem through kinetics, hot filtration and poisoning tests. ${ }^{80}$

The yield increased rapidly in the earlier stage (before 35 minutes), and then slowly and up to $99 \%$ in 60 min (Fig. S11, $\dagger$ black line). To study whether the leaching of the active species occurred during the catalytic process, $\mathbf{G O} @ \mathbf{H}-\mathbf{F e}_{\mathbf{9 5 . 7 3}} \mathbf{P d}_{\mathbf{4 . 2 6}} \mathbf{R u}_{\mathbf{0 . 0 1}}$ was removed after $15 \mathrm{~min}$, and the reaction kinetics was measured from then on. The output did not increase and basically retained the same yields (Fig. S11, $\uparrow$ red line), indicating that there was almost no leaching during catalysis. ${ }^{81}$

To further verify whether or not catalysis proceeded on the catalyst surface, poisoning experiments were carried out (Table S10†). The catalytic activity was not completely inhibited when a small amount of mercury was added to the reaction system. Mercury could not fully contact the active site of the catalyst because of the poor dispersion of mercury, and the active sites on the catalyst surface could not be completely poisoned. When 2'2-dipyridyl was added, the activity of the catalyst significantly decreased and was even almost completely deactivated, which indicated that the catalytic active sites were on the surface of $\mathbf{G O @ H - F e} \mathbf{9 5 . 7 3}_{\mathbf{9}} \mathbf{P d}_{\mathbf{4 . 2 6}} \mathbf{R u}_{\mathbf{0 . 0 1}}$. When thiophene additives were used to poison the catalyst, a yield of only $6 \%$ was obtained. Therefore, the catalytic process occurring on the surface of GO@H-Fe 95.73 $\mathbf{P d}_{4.26} \mathbf{R u}_{0.01}$ could be determined. ${ }^{82}$
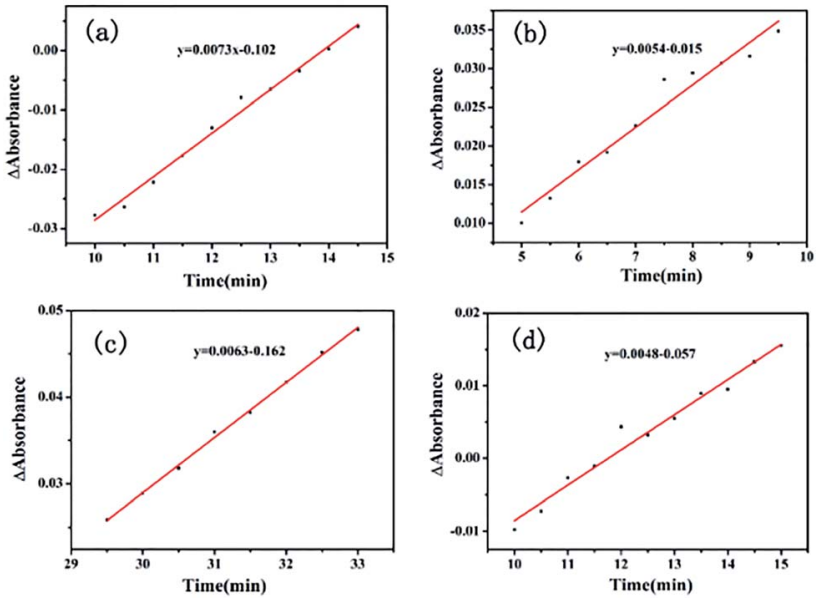

Fig. 9 ReactlR plots over time. (a) $\mathrm{GO} a \mathrm{H}-\mathrm{Fe}_{95.73} \mathrm{Pd}_{4.26} \mathrm{Ru}_{0.01}$ using the band at $754 \mathrm{~cm}^{-1}$ at $80{ }^{\circ} \mathrm{C}$, (b) $\mathrm{Li}_{2} \mathrm{PdCl}_{4} / \mathrm{FeCl}_{3} \cdot 6 \mathrm{H}_{2} \mathrm{O} / \mathrm{RuCl}_{3} \cdot x \mathrm{H}_{2} \mathrm{O}$ at $80{ }^{\circ} \mathrm{C}$. (c) GO@H-Fe ${ }_{95.73} \mathrm{Pd}_{4.26} \mathrm{Ru}_{0.01}$ using the band at $754 \mathrm{~cm}^{-1}$ at $65^{\circ} \mathrm{C}$, (d) catalyzed byLi $2 \mathrm{PdCl}_{4} / \mathrm{FeCl}_{3} \cdot 6 \mathrm{H}_{2} \mathrm{O} / \mathrm{RuCl}_{3} \cdot x \mathrm{H}_{2} \mathrm{O}$ at $65^{\circ} \mathrm{C}$. 
In situ ReactIR is usually used to investigate the catalytic process. ReactIR of the reactions catalyzed by $\mathbf{G O}$ @H-Fe $\mathbf{9 5 . 7 3}^{-}$ $\mathbf{P d}_{4.26} \mathbf{R u}_{\mathbf{0 . 0 1}}$ and $\mathrm{Li}_{2} \mathrm{PdCl}_{4} / \mathrm{FeCl}_{3} \cdot 6 \mathrm{H}_{2} \mathrm{O} / \mathrm{RuCl}_{3} \cdot x \mathrm{H}_{2} \mathrm{O}$ at different temperatures were measured, as shown in Fig. 8. For GO@H$\mathbf{F e}_{\text {95.73 }} \mathbf{P d}_{\text {4.26 }} \mathbf{R u}_{\mathbf{0 . 0 1}}$, the peak intensities at $754 \mathrm{~nm}$ increased with increasing time at different temperatures (Fig. 8a and d), and had the S-type curve with an "induction period" (Fig. $8 \mathrm{c}$ and f, black line), which was the characteristic of the heterogeneous catalysis. However, in the case of $\mathrm{Li}_{2} \mathrm{PdCl}_{4} / \mathrm{FeCl}_{3} \cdot 6 \mathrm{H}_{2} \mathrm{O} / \mathrm{RuCl}_{3}$ $\cdot x \mathrm{H}_{2} \mathrm{O}$, the induction period could not be observed (Fig. $8 \mathrm{~b}$ and e; red line), indicating the difference in the catalytic mechanism for GO@H-Fe ${ }_{95.73} \mathbf{P d}_{\mathbf{4 . 2 6}} \mathbf{R u}_{\mathbf{0 . 0 1}}$. According to the results of GO@H-Fe 95.73 $_{9} \mathbf{P d}_{4.26} \mathbf{R u}_{\mathbf{0 . 0 1}}$, the active species formed before catalysis related to the formation of the $\mathrm{Pd}$ nanoparticles, possibly $\mathrm{Ru}$, and any other transition-metal nanocluster systems. ${ }^{83}$ Then, the substrates adsorbed on the catalytic surface made contact with the active center to form intermediates, followed by the generation of products, and the desorption from the surface. ${ }^{84}$ The results obtained by the kinetic studies, hot filtration and poisoning experiments were evidence that this catalysis was a heterogeneous catalysis.

The $E_{\mathrm{a}}$ value of the heterogeneous catalysis was $9.70 \mathrm{~kJ} \mathrm{~mol}^{-1}$ $\left(k_{1}=0.0073,80^{\circ} \mathrm{C} ; k_{2}=0.0063,65^{\circ} \mathrm{C}\right.$ ) from Fig. 9a and c. Under the same conditions, the apparent activation energy of the homogeneous $\quad \mathrm{Li}_{2} \mathrm{PdCl}_{4} / \mathrm{FeCl}_{3} \cdot 6 \mathrm{H}_{2} \mathrm{O} / \mathrm{RuCl}_{3} \cdot x \mathrm{H}_{2} \mathrm{O}$ was $7.9 \mathrm{~kJ} \mathrm{~mol}^{-1}\left(k_{1}=0.0054,80^{\circ} \mathrm{C} ; k_{2}=0.0048,65^{\circ} \mathrm{C}\right)$ from Fig. $9 \mathrm{~b}$ and $\mathrm{d}$ obtained by the Arrhenius formula $k=A \times \exp \left(E_{\mathrm{a}} / R T\right)$.

The results obtained seem contradictory since the $E_{\mathrm{a}}$ (Homo) value was lower than that of $E_{\mathrm{a}}$ (Hetero). To investigate whether the supports used affect the heterogeneous reaction, the same amount of graphene oxide (GO), carbon power (CP) or Silica was applied to the homogeneous $\mathrm{Li}_{2} \mathrm{PdCl}_{4} / \mathrm{FeCl}_{3} \cdot 6 \mathrm{H}_{2} \mathrm{O} / \mathrm{RuCl}_{3} \cdot x \mathrm{H}_{2}$ $\mathrm{O}$, respectively. ${ }^{85}$ The dynamic curves of $\mathrm{Li}_{2} \mathrm{PdCl}_{4} / \mathrm{FeCl}_{3} \cdot 6 \mathrm{H}_{2} \mathrm{O}$ / $\mathrm{RuCl}_{3} \cdot x \mathrm{H}_{2} \mathrm{O}$ with GO, CP or Silica were measured as shown in Fig. S12-S14, $\dagger$ and the apparent activation energies are listed in Table S11. $\uparrow$ These apparent activation energies were higher

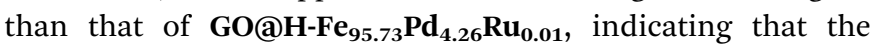
ordered heterogeneous trimetallic catalytic monolayer supported on $\mathbf{G O}$ had higher catalytic activity than those of $\mathrm{Li}_{2}$ $\mathrm{PdCl}_{4} / \mathrm{FeCl}_{3} \cdot 6 \mathrm{H}_{2} \mathrm{O} / \mathrm{RuCl}_{3} \cdot x \mathrm{H}_{2} \mathrm{O}$ mixed with GO, CP and Silica.

3.3.2 Investigation on the electrochemical impedance spectra (EIS) during catalysis. The electrochemical impedance spectroscopy (EIS) changes were also utilized for exploring what happened during the reaction process (Fig. S15 $\dagger$ ). The diameter
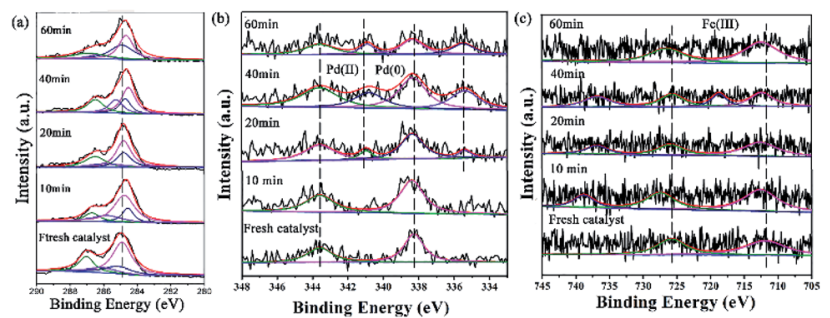

Fig. 10 XPS images of GOQH-Pd/Fe/Ru in the catalytic process and the recycled catalyst: (a) C 1s + Ru 3d, (b) Pd 3d, (c) Fe 2p. variation of EIS was incremental with increasing times, and the charge transfer resistances of GO@H-Pd/Fe/Ru increased after catalysis. It was speculated that the reduced $\mathrm{Pd}^{0}$ during the reaction made the charge transfer difficult, resulting in higher resistance. It also indicated that the stability of the used GO@H$\mathbf{P d} / \mathbf{F e} / \mathbf{R u}$ became lower than that of the fresh GO@H-Pd/Fe/ Ru. $^{72}$

\subsubsection{Investigation of the catalytic process}

3.3.3.1 Raman, SEM and TEM analysis on the catalytic process. The Raman spectra of GO@H-Fe ${ }_{95.73} \mathbf{P d}_{\mathbf{4 . 2 6}} \mathbf{R u}_{\mathbf{0 . 0 1}}$ during the reaction process are shown in Fig. S16. $\dagger$ GO@H-Fe $\mathbf{9 5 . 7 3}^{-}$ $\mathbf{P d}_{\text {4.26 }} \mathbf{R u}_{\mathbf{0 . 0 1}}$ still maintained the two characteristic D and G bands during the reaction. The shift of the two peaks was not observed during the reaction, indicating the stability of the catalyst. Compared with fresh $\mathbf{G O @ H - F e} \mathbf{9 5 . 7 3}_{\mathbf{9}} \mathbf{P d}_{\mathbf{4 . 2 6}} \mathbf{R u}_{\mathbf{0 . 0 1}}$, the recovered GO@H-Fe ${ }_{95.73} \mathbf{P d}_{\mathbf{4 . 2 6}} \mathbf{R u}_{\mathbf{0 . 0 1}}$ showed a higher $I_{\mathrm{D}} / I_{\mathrm{G}}$ strength ratio due to the micro-environment change on the surface of the catalyst. ${ }^{86}$ To investigate the morphology of the surface during the catalytic process, SEM images were measured at $0 \mathrm{~min}, 10 \mathrm{~min}, 40 \mathrm{~min}$ and $60 \mathrm{~min}$ (Fig. S17a-d $\dagger$ ). It could be seen from the images that the morphology of the GO@H-Pd/Fe/Ru monolayer had no changes at different reaction times, indicating that the catalyst still maintained the original state during the reaction process. In the case of the TEM of catalyst (Fig. S18 $\dagger$ ), almost no metal particles were observed (Fig. S17a-d $\dagger$ ) when finished in $1 \mathrm{~h}$, implying a higher stability of the catalyst.

3.3.3.2 Investigation on the arrangement of the multi-metallic catalytic monolayer. X-ray photoelectron spectroscopy (XPS) is an effective surface analysis technique to investigate the elements in the trimetallic catalytic monolayer, and is informative enough for exploring the real active center during the catalytic process ${ }^{87}$ which is dominated mainly by the metal composition on the surface and structure of the catalytic monolayer. By elucidating the true species, including its change in catalytic monolayer, the catalytic mechanism could be proposed.

Peaks of Ru at $279.80 \mathrm{eV}, 280.8 \mathrm{eV}$ were ambiguous due to the overlap with $\mathrm{C} 1 \mathrm{~s}$ and too low of a Ru quantity or low Ru content to be observed in this experiment (Fig. 10a). ${ }^{88}$ On the other hand, the peak at $284.81 \mathrm{eV}$ was attributed to the $\mathrm{C}=\mathrm{C}$ group of
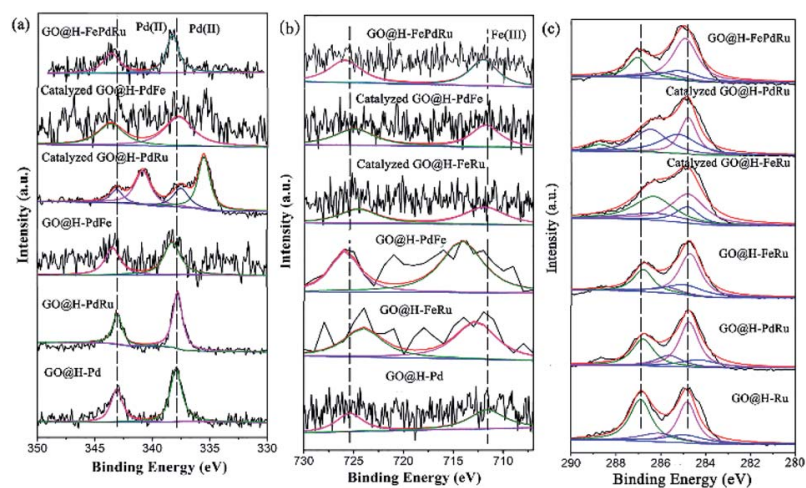

Fig. 11 XPS analysis for GOQH-Pd/Fe/Ru, Pd/Ru, Pd/Fe and Ru/Fe monolayer before and after catalysis. 
GO. The peak at $285.92 \mathrm{eV}$ was the $\mathrm{C}=\mathrm{N}$ group in the ligand, and the peaks at 286.25 and $288.16 \mathrm{eV}$ were attributed to $\mathrm{COOH}$ and $\mathrm{C}-\mathrm{OH}$, respectively. The data are listed in Table S12. $\dagger$

For GO@H-Fe $\mathbf{9 5}_{\mathbf{9 5 . 7 3}} \mathbf{P d}_{4.26} \mathbf{R u}_{\mathbf{0 . 0 1}}$, the $\mathrm{Pd}^{2+}$ species existed at an early stage. After 20 minutes of reaction, a pair of peaks appeared at 340.65 and $335.40 \mathrm{eV}$, corresponding to $\mathrm{Pd} 3 \mathrm{~d} 3 / 2$ and $3 / 5\left(\mathrm{Pd}^{0}\right)$ (Fig. 10b), indicating that the active $\mathrm{Pd}^{0}$ was formed at the beginning of the catalytic reaction. ${ }^{89}$ The intensity of the $\mathrm{Pd}^{0}$ peak increased with increasing reaction time compared to that of $\mathrm{Pd}^{2+}$, which also proved that $\mathrm{Pd}^{2+}$ was reduced to $\mathrm{Pd}^{0}$ during the catalytic reaction. The deconvolution data are presented in Table S13. $\dagger$

The XPS spectrum of Fe $2 \mathrm{p}$ displayed two characteristic peaks of $\mathrm{Fe}^{3+}$ at 711.90 and $725.70 \mathrm{eV}$ (Fig. 10c). Compared with the fresh catalysts, the binding energy of $\mathrm{Fe}^{3+}$ during catalysis moved towards higher binding energy. In addition, a satellite peak for $\mathrm{Fe}^{3+}$ at a higher $\mathrm{BE}(738.79 \mathrm{eV})$, which was very sensitive to the oxidation states, appeared after $10 \mathrm{~min}$. Two additional satellite peaks for $\mathrm{Fe}^{3+}$ at a higher $\mathrm{BE}(718.65,738.79 \mathrm{eV})$, which also was very sensitive to the oxidation states, appeared after $40 \mathrm{~min}$ and recovered after the reaction finished, meaning that $\mathrm{Fe}^{3+}$ was the electron donor during the catalytic process. ${ }^{\mathbf{9 0}}$ The deconvolution data are presented in Table S13. $\dagger$

Considering that the combination of different metals in the trimetallic monolayer has an important role in catalysis, it is plausible to propose that the proper arrangement in the multimetallic monolayer can be beneficial in enhancing the catalytic activity and stability, by bringing them together in a controlled manner. Therefore, the XPS analysis for the $\mathrm{Pd} / \mathrm{Ru}$, $\mathrm{Pd} / \mathrm{Fe}$ and $\mathrm{Ru} / \mathrm{Fe}$ monolayer used for catalysis were investigated in detail, as shown in Fig. 11. It also has to be mentioned, however, that a relatively small amount of $\mathrm{Ru}(0.01 \%)$ was present, the analyses of which are relatively difficult. Therefore, these spectra were not deconvoluted.

As is know, high activity is attributed to the sequential electronic effect among the different metals in the monolayer, and also to the electronic effect between the ligands and metals. This concept can be applied to the trimetallic nanosheet prepared, although it was hard to predict the preferable position of the Pd(II), Fe(III) and Ru(III) ions in the monolayer. ${ }^{91}$ The

Table 1 Deconvolution data for Pd $3 d$ and Fe $2 p$ of different catalysts before and after being used

\begin{tabular}{|c|c|c|c|c|c|}
\hline \multirow{2}{*}{$\frac{\text { No. }}{1}$} & \multirow{2}{*}{$\begin{array}{l}\text { Catalyst } \\
\text { GO@H-Pd }\end{array}$} & \multicolumn{2}{|c|}{ Pd 3d BE (eV) } & \multicolumn{2}{|c|}{ Fe 2p BE $(e V)$} \\
\hline & & 343.09 & 337.94 & & \\
\hline 2 & GO@H-PdRu & 343.04 & 337.80 & & \\
\hline 3 & GO@H-PdFe & 343.43 & 338.25 & 714.14 & 725.90 \\
\hline 4 & GO@H-FeRu & & & 712.74 & 724.02 \\
\hline 5 & GO@H-Ru & & & & \\
\hline 6 & GO@H-Fe & & & 711.60 & 725.40 \\
\hline 7 & Catalyzed GO@H-PdRu & 343.09 & 337.50 & & \\
\hline 8 & Catalyzed GO@H-PdFe & 343.58 & 337.70 & 711.80 & 725.00 \\
\hline 9 & Catalyzed GO@H-FeRu & & & 711.88 & 724.60 \\
\hline 10 & GO@H-PdFeRu & 343.60 & 338.20 & 711.90 & 725.70 \\
\hline 11 & Catalyzed GO@H-PdFeRu & 343.61 & 338.33 & 712.33 & 726.25 \\
\hline
\end{tabular}

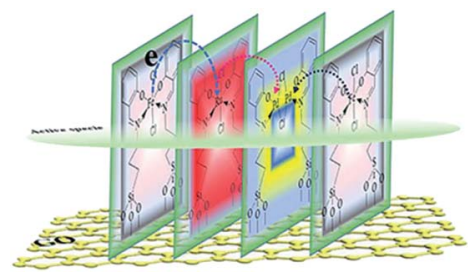

Scheme 2 Proposed arrangement of the active center in the monolayer

deconvolution data for Pd 3d and Fe 2p of the mono-, bi-, and trimetallic catalysts before and after being used for catalysis are listed in Table 1.

The BE of Pd(II) varied with various combinations, as shown in Fig. 11a. The results showed that the BE of $\mathrm{Pd}(\mathrm{II})$ shifted to lower BE after catalysis (Table 1, entries 2, 3, 7, 8, 10 and 11), implying that both $\mathrm{Fe}(\mathrm{III})$ and $\mathrm{Ru}(\mathrm{III})$ were electron donors, which could make Pd(II) more negative than boost the activity.

The BE of Fe(III) varied with various combinations, as shown in Fig. 11b. The results showed that the BE of Fe(III) shifted to higher $\mathrm{BE}$ during the catalytic process, implying that $\mathrm{Fe}$ (III) mainly was an electron donor that could make $\mathrm{Pd}(\mathrm{II})$ and $\mathrm{Ru}(\mathrm{III})$ more negative than it could boost the activity (Table 1, entries 3 , 4, 6, 8, 9, 10 and 11). The similar result for $\mathrm{Ru}$ showed that the catalyzed GO@H-Pd/Ru gave $\mathrm{Pd}^{0}$ with a ratio of $\left(\mathrm{Pd}^{0} / \mathrm{Pd}^{2+}=\right.$ 1.38), indicating that $\mathrm{Ru}$ acted as a donor to make $\mathrm{Pd}$ more negative.

Although these observed shifts were very small, the same tendency was obtained from the data, which might imply ECT from Fe to Pd, or to Ru in the monolayer. The similar ECT might also occur from $\mathrm{Ru}$ to $\mathrm{Pd}$ in the trimetallic nanosheet (Table S8†). This sequential electronic charge transfer can be illustrated, as shown in Scheme 2.

This sequence of electron transferring also could be supported and explained by the individual component function for boosting the activity. From the results of the catalytic activity for GO@H-Pd/Fe/Ru obtained above (Table S2 $\dagger$ ), GO@H-Pd/Fe exhibited a higher catalytic activity compared with that of GO@H-Pd/Ru, indicating that Fe could improve the activity more than Ru. However, if the combination of GO@H-Pd/Fe/Ru was made, it exhibited its effect to the maximum and achieved a much higher improvement in the catalytic performance, in which the activity of GO@H-Pd/Fe/Ru was two or five times

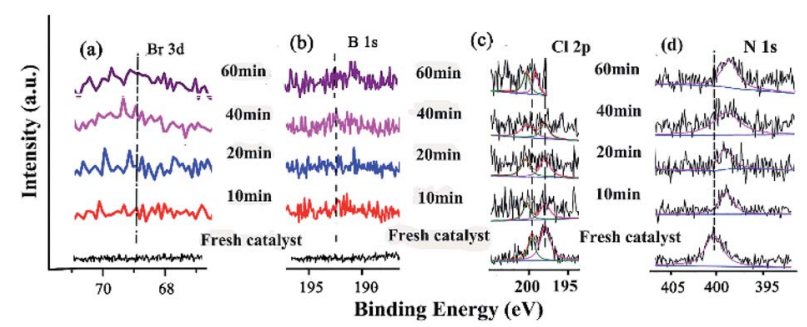

Fig. 12 XPS of the catalyst and recycled catalyst: (a) Br 3d, (b) B 1s, (c) $\mathrm{Cl} 2 \mathrm{p},(\mathrm{d}) \mathrm{N} 1 \mathrm{~s}$ 


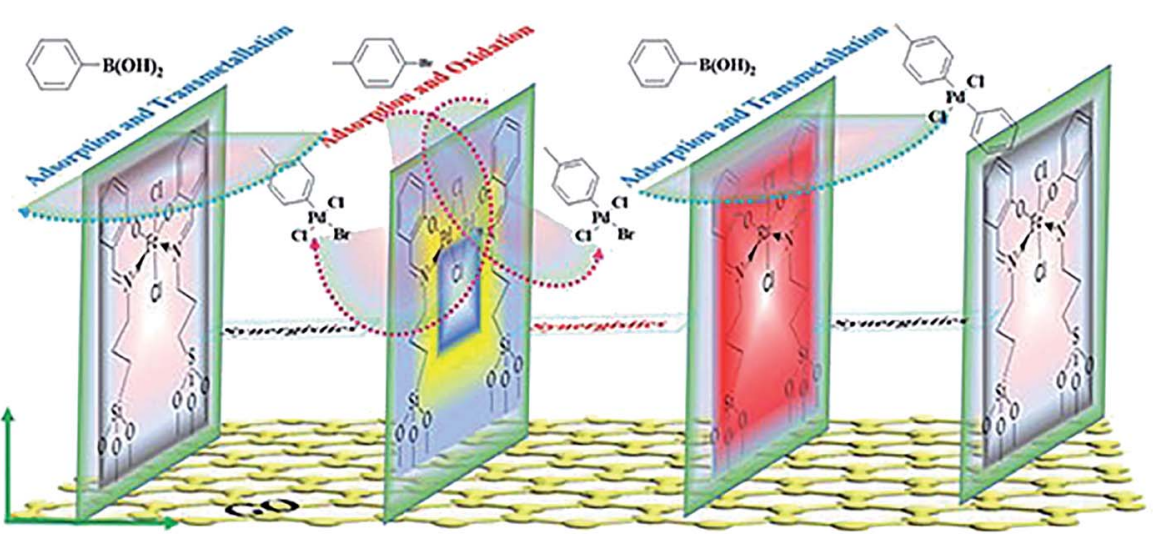

Scheme 3 Plausible catalytic mechanism in the Suzuki coupling reaction.

higher than those of GO@H-Pd/Fe and GO@H-Pd/Ru. Thus, the arrangement of these three metallic complexes in the monolayer was presumed as Fe to $\mathrm{Pd}$ to $\mathrm{Ru}$, in which a metal $\mathrm{Pd}$ (II) was juxtaposed with one $\mathrm{Fe}(\mathrm{III})$ and one $\mathrm{Ru}(\mathrm{III})$ that had a strong tendency to adsorb phenyl boronic acid (Scheme 2). It exhibited this intimate contact with the Fe and Ru to the maximum, and when combined with a high activity of Fe-Ru-Pd-Fe, achieved an improvement in the catalytic properties. ${ }^{33}$ The results also indicated that the Pd0-Ru(III)-Pd(II)-Fe(III) ensemble sites were required for the catalytic process, in which the real active sites were not only trace $\mathrm{Pd}_{0}$, but an ensemble cooperation with other metallic sites, including a ligand effect and electronic effect. It was possible for making either sites active towards crosscoupling catalysis. ${ }^{3,92}$ The XPS data indicated that the electronic structure of Pd was modified by $\mathrm{Fe}$ and $\mathrm{Ru}$, which would result only if Pd were in intimate contact with $\mathrm{Fe}$ or $\mathrm{Ru}$ (Scheme 2).

By comparing the different reaction times and the changes of $\mathrm{B} 1 \mathrm{~s}, \mathrm{Br} 3 \mathrm{p}$, and $\mathrm{N} 1 \mathrm{~s}$ in the catalytic process, it was helpful for elucidating the catalytic mechanism (Fig. 12). These three elements showed a trend of enhancement from the initial noncharacteristic peak to the characteristic peak with the extension of the reaction time. This indicated that there was a substrate adsorption process in the catalytic process.

The characterization of the changes of elements on the surface was very important for investigating the catalytic mechanism (Fig. 12). The $\mathrm{Br} 3 \mathrm{~d}$ and $\mathrm{B} 1 \mathrm{~s}$ appeared with increasing time (Fig. 12a and b), indicating that the substrates containing these elements were adsorbed and reacted at some active site. The $\mathrm{Cl} 2 \mathrm{p}$ peaks at $198.08 \mathrm{eV}$ and $199.82 \mathrm{eV}$ gradually shifted to higher BE during catalysis (Fig. 12c and Table S14†), meaning that $\mathrm{Cl}$ coordinated with $\mathrm{Pd}$ and $\mathrm{Pd}^{2+}$. In the case of $\mathrm{N}$ $1 \mathrm{~s}$ (the $\mathrm{C}=\mathrm{N}$ double bond) at $401.51 \mathrm{eV}$, the peak shifted to lower BE during catalysis (Fig. 12d and Table S14†), indicating that with the Schiff-based $\operatorname{Pd}(\mathrm{II})$ as a released precursor, the active $\operatorname{Pd}(0)$ and Schiff-base group in the ligand could stabilize and prevent the $\operatorname{Pd}(0)$ from aggregating and leaching during the reaction.

Based on the results of the Raman, SEM, TEM, and XPS analysis, the catalytic mechanism could be proposed as depicted in Scheme 3. The approach outlined here offers opportunities for both fundamental research and application, which delineated the underlying mechanistic steps on the surfaces. It was assumed that the trimetallic complexes were a pre-catalyst with certain types of active sites that had their functions in order to achieve a surface-catalyzed reaction, in which an active electron-rich Fe-Pd-Ru-Fe center was formed by synergetic between Pd, Fe and $\mathrm{Ru}$. There is a strong correlation between the catalytic activity and adjustable certain substrate adsorption capacity in the vicinity of the Fe-Pd-Ru-Fe center. Pd adsorbed $p$-bromotoluene to form an oxidation intermediate, which reacted with phenyl boronic acid adsorbed on the neighboring $\mathrm{Ru}$ or $\mathrm{Fe}$ to yield the transmetallic intermediate (Scheme 3). The presence of the $\mathrm{Ru}$ or Fe species around Pd on the surface improved the substrate adsorption, leading to a high efficiency. ${ }^{93}$

\section{Conclusions}

In summary, the trimetallic catalytic nanosheet immobilized on GO was fabricated by self-assembly. GO@H-Fe $\mathbf{9 5 . 7 3}_{\mathbf{9}} \mathbf{P d}_{\mathbf{4 . 2 6}} \mathbf{R u}_{\mathbf{0 . 0 1}}$ showed better stability and recyclability (at least 10 times with higher activity). The heterogeneous catalytic mechanism was demonstrated by kinetics, hot filtration, poisoning tests and in situ ReactIR, and the effect of the supports was also investigated in detail. The investigation of the deactivation mechanism of

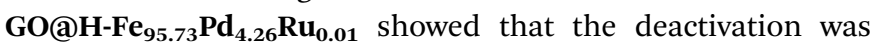
related to the agglomeration of the active species, leaching of the active species, changes of the catalyst structure, and active sites covered by residues of elements. The synergistic catalytic mechanism over the hetero-trimetallic nano-monolayer based on the results obtained above may be the following main aspects: (1) enhanced activity results from the ordered orientation of the catalytic nano-monolayer upon introducing third metal. (2) Electronic effect among these three different metals and the structure of the ligand enhanced the catalytic activity. (3) Among this trimetallic (Pd, Fe and $\mathrm{Ru}$ ) catalytic nanosheet, although $\mathrm{Fe}$ is less active, the doping of $\mathrm{Fe}$ or $\mathrm{Ru}$ to Pd can effectively enhance the entire activity of the trimetallic nanosheet. The presence of Fe made Pd more negative and increased 
the stability of the catalyst. The Ru metal adjacent to Pd helps to activate the substrate molecules adsorbed on $\mathrm{Ru}$, and made it easy for the trans-metalation step.

\section{Conflicts of interest}

There are no conflicts to declare.

\section{Acknowledgements}

This work was supported by the NSFC (21861132002), and the Henan Natural Science Foundation of China (192102210046).

\section{Notes and references}

1 C. M. Friend and B. Xu, Acc. Chem. Res., 2017, 50, 517-521.

2 A. Toshima and T. Yonezawa, New J. Chem., 1998, 1179-1201.

3 M. S. Kutubi, K. Sato, K. Wada, T. Yamamoto, S. Matsumura, K. Kusada, H. Kobayashi, H. Kitagawa and K. Nagaoka, ChemCatChem, 2015, 7, 3887-3894.

4 P. P. Huang, Z. Q. Xue, T. S. Li, Z. Y. Liu, D. H. Wei, M. H. Liu and Y. J. Wu, ChemCatChem, 2018, 10, 5141-5155.

5 H.-L. Jiang and Q. Xu, J. Mater. Chem., 2011, 21, 13705.

6 P. Buchwalter, J. Rosé and P. Braunstein, Chem. Rev., 2015, 115, 28-126.

7 C. Wang, D. van der Vliet, K. L. More, N. J. Zaluzec, S. Peng, S. Sun, H. Daimon, G. Wang, J. Greeley, J. Pearson, A. P. Paulikas, G. Karapetrov, D. Strmcnik, N. M. Markovic and V. R. Stamenkovic, Nano Lett., 2011, 11, 919-926.

8 V. Mazumder, M. F. Chi, K. L. More and S. H. Sun, J. Am. Chem. Soc., 2010, 132, 7848-7849.

9 S. R. Borhade and S. B. Waghmode, Beilstein J. Org. Chem., 2011, 7, 310-319.

10 K. K. Senapati, S. Roy, C. Borgohain and P. Phukan, J. Mol. Catal. A: Chem., 2012, 352, 128-134.

11 T. Baran, J. Colloid Interface Sci., 2017, 496, 446-455.

12 F. Shi, M. K. Tse, S. Zhou, M.-M. Pohl, J. Radnik, S. Hubner, K. Jahnisch, A. Bruckner and M. Beller, J. Am. Chem. Soc., 2009, 131, 1775-1779.

13 D. V. Aleksanyan, S. G. Churusova, Z. S. Klemenkova, R. R. Aysin, E. Y. Rybalkina, Y. V. Nelyubina, O. I. Artyushin, A. S. Peregudov and V. A. Kozlov, Organometallics, 2019, 38, 1062-1080.

14 J. Chen, M. Qiao, W. Wang and Q. Zhang, Composites Communications, 2019, 16, 41-49.

15 K. Hong, M. Sajjadi, J. M. Suh, K. Zhang, M. Nasrollahzadeh, H. W. Jang, R. S. Varma and M. Shokouhimehr, ACS Appl. Nano Mater., 2020, 3, 2070-2103.

16 P. Huang, E. Song, Y. Sun, T. Li, D. Wei, M. Liu and Y. Wu, Mol. Catal., 2019, 469, 75-86.

17 M. J. Clarke, Coord. Chem. Rev., 2003, 236, 209-233.

18 T. Komanoya, T. Kinemura, Y. Kita, K. Kamata and M. Hara, J. Am. Chem. Soc., 2017, 139, 11493-11499.

19 B. Li, J. Wang, Y. Yuan, H. Ariga, S. Takakusagi and K. Asakura, ACS Catal., 2011, 1, 1521-1528.
20 D. Zhang, H. Zhao, B. Huang, B. Li, H. Li, Y. Han, Z. Wang, X. Wu, Y. Pan, Y. Sun, X. Sun, J. Lai and L. Wang, ACS Cent. Sci., 2019, 5, 1991-1997.

21 J. J. Willis, E. D. Goodman, L. Wu, A. R. Riscoe, P. Martins, C. J. Tassone and M. Cargnello, J. Am. Chem. Soc., 2017, 139, 11989-11997.

22 B. Han, A. Grimaud, L. Giordano, W. T. Hong, O. DiazMorales, L. Yueh-Lin, J. Hwang, N. Charles, K. A. Stoerzinger, W. Yang, M. T. M. Koper and Y. ShaoHorn, J. Phys. Chem. C, 2018, 122, 8445-8454.

23 D. S. Müller, Y. Raoul, J. Le Nôtre, O. Baslé and M. Mauduit, ACS Catal., 2019, 9, 3511-3518.

24 B.-J. Kim, E. Fabbri, D. F. Abbott, X. Cheng, A. H. Clark, M. Nachtegaal, M. Borlaf, I. E. Castelli, T. Graule and T. J. Schmidt, J. Am. Chem. Soc., 2019, 141, 5231-5240.

25 C. Chitpakdee, A. Junkaew, P. Maitarad, L. Shi, V. Promarak, N. Kungwan and S. Namuangruk, Chem. Eng. J., 2019, 369, 124-133.

26 Ö. Metin, S. F. Ho, C. Alp, H. Can, M. N. Mankin, M. S. Gültekin, M. Chi and S. Sun, Nano Res., 2012, 6, 10-18.

27 A. Kilic, I. Yilmaz, M. Ulusoy and E. Tas, Appl. Organomet. Chem., 2008, 22, 494-502.

28 J.-Q. Du, Y. Zhang, T. Tian, S.-C. Yan and H.-T. Wang, Mater. Res. Bull., 2009, 44, 1347-1351.

29 Q. Fu, Y. Meng, Z. Fang, Q. Hu, L. Xu, W. Gao, X. Huang, Q. Xue, Y. P. Sun and F. Lu, ACS Appl. Mater. Interfaces, 2017, 9, 2469-2476.

30 P. Venkatesan and J. Santhanalakshmi, J. Mol. Catal. A: Chem., 2010, 326, 99-106.

31 C. K. Ostrom and A. Chen, J. Phys. Chem. C, 2013, 117, 20456-20464.

32 L. Rubinovich and M. Polak, Phys. Rev. B, 2004, 69, 155405.

33 S. Imamura, Y. Okumura, T. Nishio, K. Utani and Y. Matsumura, Ind. Eng. Chem. Res., 1998, 37, 1136-1139.

34 Y. Yang, A. C. Reber, S. E. Gilliland, C. E. Castano, B. F. Gupton and S. N. Khanna, J. Catal., 2018, 360, 20-26.

35 X. Gu, S. Bi, L. Guo, Y. Zhao, T. Li, M. Liu, P. Chen and Y. Wu, ACS Omega, 2017, 2, 5415-5433.

36 M. K. Samantaray, V. D'Elia, E. Pump, L. Falivene, M. Harb, S. Ould Chikh, L. Cavallo and J.-M. Basset, Chem. Rev., 2020, 120, 734-813.

37 W. Shang, X. Zeng, T. Li, W. Xu, D. Wei, M. Liu and Y. Wu, J. Catal., 2019, 376, 228-237.

38 J. Yuan and M. H. Liu, J. Am. Chem. Soc., 2003, 125, 50515056.

39 B. Mu, T. Li, C. Li, P. Liu, W. Shang and Y. Wu, Tetrahedron, 2009, 65, 2599-2604.

40 X. Huang, S. Jiang, X. S. Wang, B. Zhang and M. H. Liu, J. Am. Chem. Soc., 2004, 126, 1322-1323.

41 W. Xu, T. Li, G. Li, Y. Wu and T. Miyashita, J. Photochem. Photobiol., A, 2011, 219, 50-57.

42 Z. Shen, Y. Jiang, T. Wang and M. Liu, J. Am. Chem. Soc., 2015, 137, 16109-16115.

43 Y. F. Qiu, P. L. Chen and M. H. Liu, J. Am. Chem. Soc., 2010, 132, 9644-9652.

44 Z. Fu, T. Li, B. Mu, L. Mao, G. Li, W. Xu and Y. Wu, J. Mol. Catal. A: Chem., 2012, 363, 200-207. 
45 C. Bai, Q. Zhao, Y. Li, G. Zhang, F. Zhang and X. Fan, Catal. Lett., 2014, 144, 1617-1623.

46 M. Xiao, L. Feng, J. Zhu, C. Liu and W. Xing, Nanoscale, 2015, 7, 9467-9471.

47 J. Wang, B. Mu, Z. Fu, L. Wang, T. Li and Y. Wu, Chin. J. Catal., 2014, 35, 1059-1067.

48 B. Mu, T. Li, J. Li and Y. Wu, J. Organomet. Chem., 2008, 693, 1243-1251.

49 B. Mu, T. Li, Z. Fu and Y. Wu, Catal. Commun., 2009, 10, 1497-1501.

50 Z. H. Fu, N. Zhang, T. S. Li, W. J. Xu and Y. J. Wu, J. Colloid Interface Sci., 2013, 394, 409-418; N. Zhao, T. S. Li, Z. Zhai, J. J. Qiu, W. J. Xu, M. H. Liu and Y. J. Wu, ChemCatChem, 2013, 5, 1481-1489.

51 Z. Fu, T. Li, X. He, J. Liu, W. Xu and Y. Wu, J. Mol. Catal. A: Chem., 2014, 395, 293-299.

52 H. Liu, T. Li, X. Xue, W. Xu and Y. Wu, Catal. Sci. Technol., 2016, 6, 1667-1676.

53 L. Wang, P. Huang, J. Yang, T. Li, L. Mao, M. Liu and Y. Wu, RSC Adv., 2018, 8, 31860-31867.

54 E. Song, J. Wang, T. Li, W. Zhao, M. Liu and Y. Wu, Mol. Catal., 2020, 482, 110671.

55 L. Li, X. Xue, Y. Sun, W. Zhao, T. Li, M. Liu and Y. Wu, Chem. Res. Chin. Univ., 2020, 36, 821-828.

56 J. Zhao, K. Jarvis, P. Ferreira and A. Manthiram, J. Power Sources, 2011, 196, 4515-4523.

57 S. J. Hoseini, V. Heidari and H. Nasrabadi, J. Mol. Catal. A: Chem., 2015, 396, 90-95.

58 J. Hu, Y. Wang, M. Han, Y. Zhou, X. Jiang and P. Sun, Catal. Sci. Technol., 2012, 2, 2332-2340.

59 H. Yuan, H. Liu, B. Zhang, L. Zhang, H. Wang and D. S. Su, Phys. Chem. Chem. Phys., 2014, 16, 11178-11181.

60 Y. Yang, A. C. Reber, S. E. Gilliland, C. E. Castano, B. F. Gupton and S. N. Khanna, J. Phys. Chem. C, 2018, 122, 25396-25403.

61 R. Ren, S. Bi, L. Wang, W. Zhao, D. Wei, T. Li, W. Xu, M. Liu and Y. Wu, RSC Adv., 2020, 10, 23080-23090.

62 M. Görlin, J. Ferreira de Araújo, H. Schmies, D. Bernsmeier, S. Dresp, M. Gliech, Z. Jusys, P. Chernev, R. Kraehnert, H. Dau and P. Strasser, J. Am. Chem. Soc., 2017, 139, 20702082.

63 Y. Deng, C. Luo, J. Zhang, D. Qiu, T. Cao, Q. Lin, W. Lv, F. Kang and Q.-H. Yang, Sci. China Mater., 2018, 62, 745-750. 64 N. Shang, C. Feng, H. Zhang, S. Gao, R. Tang, C. Wang and Z. Wang, Catal. Commun., 2013, 40, 111-115.

65 N. Shang, S. Gao, C. Feng, H. Zhang, C. Wang and Z. Wang, RSC Adv., 2013, 3, 21863-21868.

66 C. Thomas, Coord. Chem. Rev., 2003, 243, 125-142.

67 Z. Xue, P. Huang, T. Li, P. Qin, D. Xiao, M. Liu, P. Chen and Y. Wu, Nanoscale, 2017, 9, 781-791.

68 N. A. Isley, F. Gallou and B. H. Lipshutz, J. Am. Chem. Soc., 2013, 135, 17707-17710.

69 W. Wang, Y. Wang and G.-C. Wang, J. Phys. Chem. C, 2017, 121, 6820-6834.
70 R. Raja, S. Hermans, D. S. Shephard, S. Bromley, J. M. Thomas and B. F. G. Johnson, Chem. Commun., 1999, 1571-1572.

71 W. Li, G. Lv, X. Cheng, R. Sang, X. Ma, Y. Zhang, R. Nie, J. Li, M. Guan and Y. Wu, Tetrahedron, 2016, 72, 8557-8564.

72 Y. Li, N. Li, K. Yanagisawa, X. Li and X. Yan, Mater. Res. Bull., 2015, 65, 110-115.

73 H. Naeimi and F. Kiani, J. Organomet. Chem., 2019, 885, 6572.

74 M. Rajabzadeh, R. Khalifeh, H. Eshghi and M. Bakavoli, J. Catal., 2018, 360, 261-269.

75 A. S. Roy, J. Mondal, B. Banerjee, P. Mondal, A. Bhaumik and S. M. Islam, Appl. Catal., A, 2014, 469, 320-327.

76 W. Tang, J. Li, X. Jin, J. Sun, J. Huang and R. Li, Catal. Commun., 2014, 43, 75-78.

77 Q. Wu, A. Nouara, Y. Li, M. Zhang, W. Wang, M. Tang, B. Ye, J. Ding and D. Wang, Chemosphere, 2013, 90, 1123-1131.

78 W. Xu, H. Sun, B. Yu, G. Zhang, W. Zhang and Z. Gao, ACS Appl. Mater. Interfaces, 2014, 6, 20261-20268.

79 K. Mishra and Y. R. Lee, J. Catal., 2019, 376, 77-86.

80 W. Shi, X. Chen, S. Xu, J. Cui and L. Wang, Nano Res., 2016, 9, 2912-2920.

81 K. M. K. Yu, P. Meric and S. C. Tsang, Catal. Today, 2006, 114, 428-433.

82 D. S. Su, S. Perathoner and G. Centi, Chem. Rev., 2013, 113, 5782-5816.

83 C. Besson and R. G. Finke, Chem. Mater., 2005, 17, 49254938.

84 R. Awasthi and R. N. Singh, Carbon, 2013, 51, 282-289.

85 R. Galaverna, M. C. Breitkreitz and J. C. Pastre, ACS Sustainable Chem. Eng., 2018, 6, 4220-4230.

86 S. Thunga, S. Poshala, N. Anugu, R. Konakanchi, S. Vanaparthi and H. P. Kokatla, Tetrahedron Lett., 2019, 60, 2046-2048.

87 S. G. K. R. Harikumar and C. N. R. Rao, J. Phys. Chem. A, 1997, 101, 536-540.

88 H. Wang, S. Chen, C. Wang, K. Zhang, D. Liu, Y. A. Haleem, X. Zheng, B. Ge and L. Song, J. Phys. Chem. C, 2016, 120, 6569-6576.

89 T. Tamoradi, M. Ghadermazi and A. GhorbaniChoghamarani, J. Saudi Chem. Soc., 2019, 23, 846-855.

90 T. Yamashita and P. Hayes, Appl. Surf. Sci., 2008, 254, 24412449.

91 N. Toshima, R. Ito, T. Matsushita and Y. Shiraishi, Catal. Today, 2007, 122, 239-244.

92 A. Tompos, M. Hegedus, A. Szegedi, J. L. G. Fierro and S. Rojas, Comb. Chem. High Throughput Screening, 2007, 10, 71-82.

93 L. Gregor, A. K. Reilly, T. A. Dickstein, S. Mazhar, S. Bram, D. G. Morgan, Y. Losovyj, M. Pink, B. D. Stein, V. G. Matveeva and L. M. Bronstein, ACS Omega, 2018, 3, 14717-14725. 